\title{
Article \\ Comparison of the Nucleation Parameters of Aqueous L-glycine Solutions in the Presence of L-arginine from Induction Time and Metastable-Zone-Width Data
}

\author{
Lie-Ding Shiau ${ }^{1,2}$ (D)
}

1 Department of Chemical and Materials Engineering, Chang Gung University, Taoyuan 333, Taiwan; shiau@mail.cgu.edu.tw; Tel.: +886-3-2118800 (ext. 5291)

2 Department of Urology, Linkou Chang Gung Memorial Hospital, Taoyuan 333, Taiwan

check for

updates

Citation: Shiau, L.-D. Comparison of the Nucleation Parameters of Aqueous L-glycine Solutions in the Presence of L-arginine from Induction Time and Metastable-Zone-Width Data. Crystals 2021, 11, 1226. https:// doi.org/10.3390/cryst11101226

Academic Editors: Heike Lorenz, Alison Emslie Lewis, Erik Temmel and Jens-Petter Andreassen

Received: 14 September 2021

Accepted: 11 October 2021

Published: 12 October 2021

Publisher's Note: MDPI stays neutral with regard to jurisdictional claims in published maps and institutional affiliations.

Copyright: (C) 2021 by the author. Licensee MDPI, Basel, Switzerland. This article is an open access article distributed under the terms and conditions of the Creative Commons Attribution (CC BY) license (https:/ / creativecommons.org/licenses/by/ $4.0 /)$.

\begin{abstract}
Induction time and metastable-zone-width (MSZW) data for aqueous L-glycine solutions in the presence of L-arginine impurity were experimentally measured using a turbidity probe in this study. The nucleation parameters, including the interfacial free energy and pre-exponential nucleation factor, obtained from induction time data, were compared with those obtained from MSZW data. The influences of lag time on the nucleation parameters were examined for the induction time data. The effects of L-arginine impurity concentration on the nucleation parameters based on both the induction time and MSZW data were investigated in detail.
\end{abstract}

Keywords: crystallites; impurities; induction time; metastable zone width; nucleation parameters

\section{Introduction}

In crystal growth, the induction time is defined as the time interval between the establishment of the supersaturated state and the formation of detectable nuclei. The metastable-zone-width (MSZW) limit is defined as the time taken at a given cooling rate between the establishment of the supersaturated state and the formation of detectable nuclei. Nucleation is the initial process for the formation of crystals in liquid solutions. Thus, both the induction time and MSZW data are related to the nucleation rate of the crystallized substance in solutions. In classical nucleation theory (CNT) [1-3], the nucleation rate is expressed in the Arrhenius form, governed by two nucleation parameters, including the interfacial free energy and pre-exponential nucleation factor. The interfacial free energy is the energy required to create a new solid/liquid interface for the formation of crystals in liquid solutions, while the pre-exponential factor is related to the attachment rate of solute molecules to a cluster in the formation of crystals. The influences of impurities on the nucleation parameters have long been investigated using induction time or MSZW data with the addition of different impurities in solutions for a variety of compounds [4-14].

The nucleation parameters of a crystallized substance have been traditionally determined from induction time data by assuming $t_{i}^{-1} \propto J$, where $J$ is nucleation rate [1] Recently, various methods have been proposed to calculate the nucleation parameters from MSZW data [15-21]. Although the induction time and MSZW processes are two different temperature-controlling methods for determination of the nucleation parameters in a crystallization system, a model should be available to relate the induction time and MSZW data with the nucleation parameters. Furthermore, as a cooling process is applied first to reach the desired operating temperature and then a constant temperature is adopted in the induction time measurements, there always exists a lag time between the prepared supersaturated solution being at a higher temperature and it being cooled to the desired lower constant temperature. For simplicity, the lag time is usually neglected in determining the nucleation parameters from the induction time data.

The nucleation process can behave differently. For certain systems, induction time cannot even be considered due to sharp phase transition, while for some cases there is 
induction time governed by different material properties. For example, by evaporating a cellulose nanocrystal-based cholesteric drop, the drop edges are pinned to the substrate, which leads to nonequilibrium sliding of the individual cholesteric fragment with active ordering [22]; following the induction period of cholesteric collagen tactoids, phase separation goes through the nucleation process during which multiple chiral nuclei spontaneously emerge and grow throughout the continuous isotropic phase [23]. In the present work, a model was proposed based on CNT to relate the induction time and MSZW data with the nucleation parameters for the systems with an experimentally measurable nucleation point. The proposed model was then applied to determine the nucleation parameters for the aqueous L-glycine solutions in the presence of L-arginine impurity from the induction time and MSZW data. The effects of lag time on the nucleation parameters within the induction time data were investigated. L-glycine was adopted in this work as it is the simplest amino acid and is often used as a model compound in the study of solution nucleation [24-30]. $\mathrm{L}$-arginine is another amino acid which was randomly chosen as impurity in the aqueous L-glycine solutions.

\section{Theory}

The nucleation rate according to CNT is expressed as [1-3]

$$
J=A \exp \left[-\frac{16 \pi v^{2} \gamma^{3}}{3 k_{B}{ }^{3} T^{3} \ln ^{2} S}\right],
$$

where $A$ is the nucleation pre-exponential factor, $\gamma$ is the interfacial free energy, $k_{B}$ is the Boltzmann constant, $v=M_{w} / \rho_{c} N_{A}$ is the molecular volume, $T$ is the temperature, and $S$ is the supersaturation.

A model is derived based on CNT to determine $\gamma$ and $A$ by relating the induction time and MSZW data with $J$ as follows. If a solution saturated at $T_{0}$ is cooled to $T_{m}$ at a constant cooling rate $b$ within the time period $t=0$ to $t_{m}$ and then the temperature is kept at $T_{m}$ within the time period $t_{m}$ to $t_{m}+t_{i}$, the nucleation event for this combined process is assumed to be detected at $t=t_{m}+t_{i}$. If $t_{m}$ is small compared to $t_{i}$, this combined process can be regard as the induction time process with consideration of the lag time $t_{m}$, which is the time required for the solution saturated at $T_{0}$ to cool to $T_{m}$ at cooling rate $b$. Thus, $\Delta T_{m}=T_{0}-T_{m}$ and the lag time is given by $t_{m}=\Delta T_{m} / b$. This combined process for $t_{m}=0$ corresponds to the induction time process without consideration of the lag time. On the other hand, this combined process for $t_{i}=0$ corresponds to the MSZW process.

Figure 1 depicts the MSZW process for a saturated solution of $C_{0}$ cooled at a constant cooling rate $b$, where $T_{0}$ is the initial saturated temperature at $t=0, T_{m}$ is the nucleation temperature at $t_{m}, C_{0}$ is the saturated concentration at $T_{0}, C_{m}$ is the saturated concentration at $T_{m}, C_{e q}(T)$ is the solubility, and $S(T)=C_{0} / C_{e q}(T)$ is the supersaturation. As $C_{e q}(T)$ generally decreases with decreasing temperature, $S(T)$ increases and subsequently $J$ increases with time. For the nucleation point at $t_{m}, S_{m}$ is the supersaturation at $T_{m}$ defined as $S_{m}=C_{0} / C_{e q}\left(T_{m}\right)=C_{0} / C_{m}$. The nucleation rate at $T_{m}$ is given by

$$
J_{m}=A \exp \left[-\frac{16 \pi v^{2} \gamma^{3}}{3 k_{B}{ }^{3} T_{m}{ }^{3} \ln ^{2} S_{m}}\right] .
$$




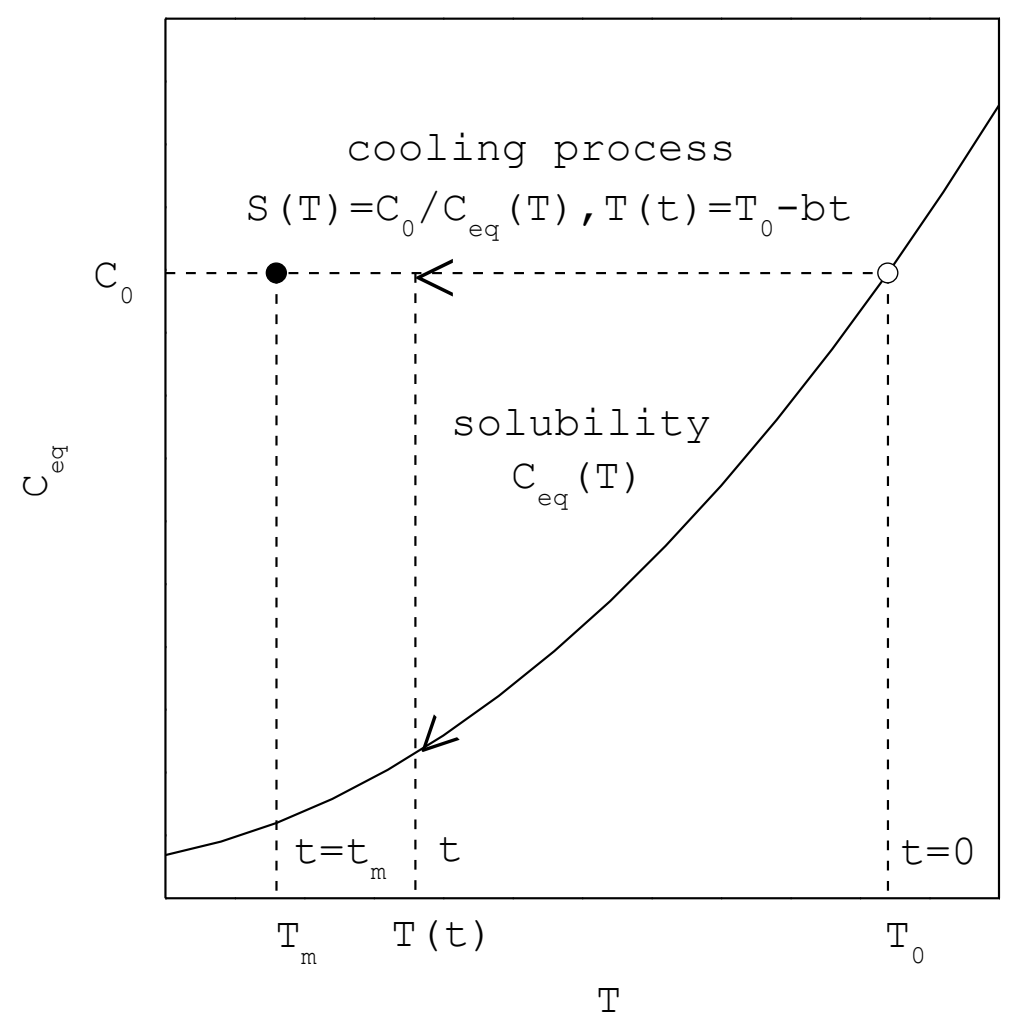

Figure 1. A schematic diagram showing the increasing of supersaturation during the cooling process reproduced from Shiau [31], where $C_{e q}(T)$ is the temperature-dependent solubility ( $\bigcirc$ represents the starting point and $\bullet$ represents the nucleation point).

Note that both $S_{m}$ and $\Delta T_{m}$ are measures of the MSZW.

As the first appearance of nuclei can be regarded as a random process, the stochastic process of nucleation can be described by the Poisson's law [32-34]. For the combined process described above, as the temperature is cooled from $T_{0}$ to $T_{m}$ within the time period $t=0$ to $t_{m}, S(T)$ increases and $J$ increases with time; and as the temperature is kept at $T_{m}$ within the time period $t_{m}$ to $t_{m}+t_{i}$, the supersaturation remains the same at $S_{m}$ and $J$ remains the same at $J_{m}$. Based on the given reasoning, the average number of expected nuclei $N$ in a solution volume $V$ within the time period $t=0$ to $t_{m}+t_{i}$ is proposed in this study as

$$
N=\left(\int_{0}^{t_{m}} J V d t\right)+J_{m} V t_{i} .
$$

where the first term on the right-hand side represents the average number of expected nuclei generated within the time period $t=0$ to $t_{m}$ and the second term on the right-hand side represents the average number of expected nuclei generated within the time period $t_{m}$ to $t_{m}+t_{i}$.

Based on the two-point trapezoidal rule for computing the value of a definite integral, one can derive [35]

$$
\int_{0}^{t_{m}} J V d t=\frac{1}{2}\left(J_{0}+J_{m}\right) V t_{m}=\frac{J_{m} V \Delta T_{m}}{2 b},
$$

where $J_{0}$ and $J_{m}$ represent the nucleation rate at $t=0$ and $t=t_{m}$, respectively. Note that $J_{0}=0$ at $t=0$ when $S\left(T_{0}\right)=1$ and $t_{m}=\Delta T_{m} / b$.

According to the single nucleus mechanism (SNM) proposed by some researchers through experimental validation [32-34], a single primary nucleus is formed in a supersaturated solution, which grows out to a particular size and undergoes secondary nucleation by 
crystal-stirring-impeller or crystal-wall collision. Based on the assumptions that the growth time between the formation of nucleus and growth to the minimum size for secondary nucleation is negligible, and one secondary nucleation is enough to generate detectable crystal volume increase in a negligible amount of time, the nucleation event is detected after the secondary nucleation of the single primary nucleus. Thus, the nucleation event for the combined process occurs at $t=t_{m}+t_{i}$ when the first nucleus is formed. By substituting $N=1$ in Equation (3), combining Equations (2)-(4) leads to

$$
\ln \left(\frac{\Delta T_{m}}{2 b}+t_{i}\right)=-\ln (A V)+\frac{16 \pi v^{2} \gamma^{3}}{3 k_{B}^{3} T_{m}^{3} \ln ^{2} S_{m}} .
$$

Thus, Equation (5) can be applied to determine the nucleation parameters from the induction time data, $t_{i}$, with consideration of the lag time, $\Delta T_{m} / b$. A plot of $\ln \left(\Delta T_{m} / 2 b+t_{i}\right)$ versus $\ln ^{2} S_{m}$ should give a straight line, the slope and intercept of which permit determination of $\gamma$ and $A$, respectively.

Equation (5) for $\Delta T_{m} / b=0$ reduces to

$$
\ln t_{i}=-\ln (A V)+\frac{16 \pi v^{2} \gamma^{3}}{3 k_{B}{ }^{3} T_{m}{ }^{3} \ln ^{2} S_{m}},
$$

Which corresponds to the conventional method adopted in determination of $\gamma$ and $A$ from the induction time data without consideration of the lag time. Equation (5) for $t_{i}=0$ reduces to

$$
\ln \left(\frac{\Delta T_{m}}{2 b}\right)=-\ln (A V)+\frac{16 \pi v^{2} \gamma^{3}}{3 k_{B}^{3} T_{m}^{3} \ln ^{2} S_{m}}
$$

Which can be applied to determine $\gamma$ and $A$ from the MSZW measurements, where a solution saturated at $T_{0}$ is cooled at a constant rate $b$ from $t=0$ to $t_{m}$ and the nucleation event is detected at $T_{m}$.

If the temperature-dependent solubility is described in terms of the van't Hoff Equation (1), one obtains

$$
\ln S_{m}=\ln \left(\frac{C_{0}}{C_{m}}\right)=\frac{-\Delta H_{d}}{R_{G}}\left(\frac{1}{T_{0}}-\frac{1}{T_{m}}\right)=\left(\frac{\Delta H_{d}}{R_{G} T_{0}}\right)\left(\frac{\Delta T_{m}}{T_{m}}\right),
$$

where $\Delta H_{d}$ is the heat of dissolution and $R_{G}$ is the gas constant. Substituting $\ln S_{m}$ in Equation (8) into Equation (7) yields

$$
\left(\frac{T_{0}}{\Delta T_{m}}\right)^{2}=\frac{3}{16 \pi}\left(\frac{k_{B} T_{0}}{v^{2 / 3} \gamma}\right)^{3}\left(\frac{\Delta H_{d}}{R_{G} T_{0}}\right)^{2}\left[\ln \left(\frac{\Delta T_{m}}{b}\right)+\ln \left(\frac{A V}{2}\right)\right] .
$$

A plot of $\left(T_{0} / \Delta T_{m}\right)^{2}$ versus $\ln \left(\Delta T_{m} / b\right)$ based on the MSZW data should give a straight line, the slope and intercept of which permit determination of $\gamma$ and $A$, respectively. Equation (9) is consistent with the result developed by Shiau and $\mathrm{Wu}$ [21] in determination of $\gamma$ and $A$ from the MSZW data.

\section{Experimental Methods}

Deionized water, L-glycine (>99\%, Alfa Aesar) and L-arginine (>98\%, ACROS) were used to prepare the desired supersaturated solution for the specified impurity concentration. The experimental apparatus adopted by Shiau and Lu [18] was used in the study of nucleation, which consists of a $250 \mathrm{~mL}$ crystallizer equipped with a magnetic stirrer at a constant stirring rate of $350 \mathrm{rpm}$, immersed in programmable thermostatic water. A turbidity probe with a near-infrared source (Crystal Eyes manufactured by HEL limited, Hertford, UK) was used to detect the nucleation event.

The solubility of L-glycine in water from $303 \mathrm{~K}$ to $318 \mathrm{~K}$ was measured in this work. The solubility measurements indicated that the solubility of L-glycine in water was nearly not 
influenced by the presence of L-arginine ranging from $C_{i m}=0-10 \mathrm{~kg}$ arginine $/ \mathrm{m}^{3}$ solution, which corresponds to $0-0.02 \mathrm{~mol}$ arginine/mol glycine. The measured solubility of Lglycine in water was consistent with the solubility data reported by Park et al. [36]. In terms of the van't Hoff equation for the measured solubility, one obtains $\Delta H_{d}=10.2 \mathrm{~kJ} / \mathrm{mol}$ with $C_{e q}(303 \mathrm{~K})=215 \mathrm{~kg} / \mathrm{m}^{3}$ and $C_{e q}(318 \mathrm{~K})=261 \mathrm{~kg} / \mathrm{m}^{3}$ in this work.

For the induction time and MSZW experiments, a $200 \mathrm{~mL}$ aqueous L-glycine solution $\left(V=2 \times 10^{-4} \mathrm{~m}^{3}\right)$ at the desired concentration was held at $5 \mathrm{~K}$ above the saturated temperature for $20 \mathrm{~min}$ to ensure a complete dissolution at the beginning of the experiments, which was also confirmed by the turbidity measurement. In the induction time experiments, the induction time and lag time data were measured by rapidly cooling the supersaturated solution at various supersaturations to $303 \mathrm{~K}$. In the MSZW experiments, MSZW data were measured by cooling the solution saturated at $318 \mathrm{~K}$ with different constant cooling rates. Each run was carried out at least three times at each condition for the solubility, the induction time, and the MSZW measurements.

Although L-glycine can be crystallized in different polymorphs, including $\alpha$-form, $\beta$ form and $\gamma$-form, $\alpha$-form is usually obtained from pure aqueous L-glycine solutions [24-30]. In this work, the final dried crystals at the end of the experiments were analyzed using Raman spectroscopy (P/N LSI-DP2-785 Dimension-P2 System, $785 \mathrm{~nm}$, manufactured by Lambda Solutions, INC., Seattle, WA, USA) to validate the polymorph of the L-glycine crystals. By comparing with the Raman spectra of $\alpha$-form crystals reported by Murli et al. [37], it was found that $\alpha$-form L-glycine crystals were formed from aqueous L-glycine solutions in this work for various supersaturations without and with the presence of L-arginine impurity. Figure 2 shows some Raman spectra of the L-glycine crystals obtained in this work at $S=1.07$ and $S=1.12$ for $C_{i m}=0$ and $C_{i m}=10 \mathrm{~kg} / \mathrm{m}^{3}$, respectively.

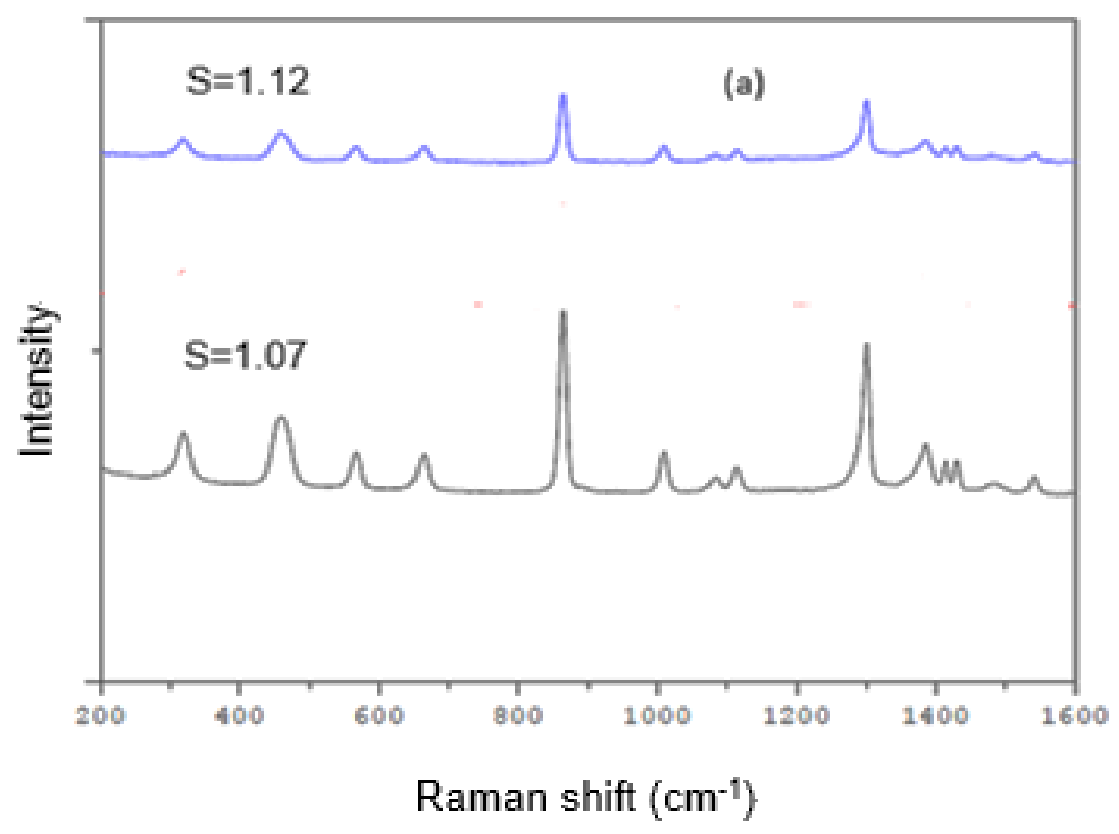

Figure 2. Cont. 


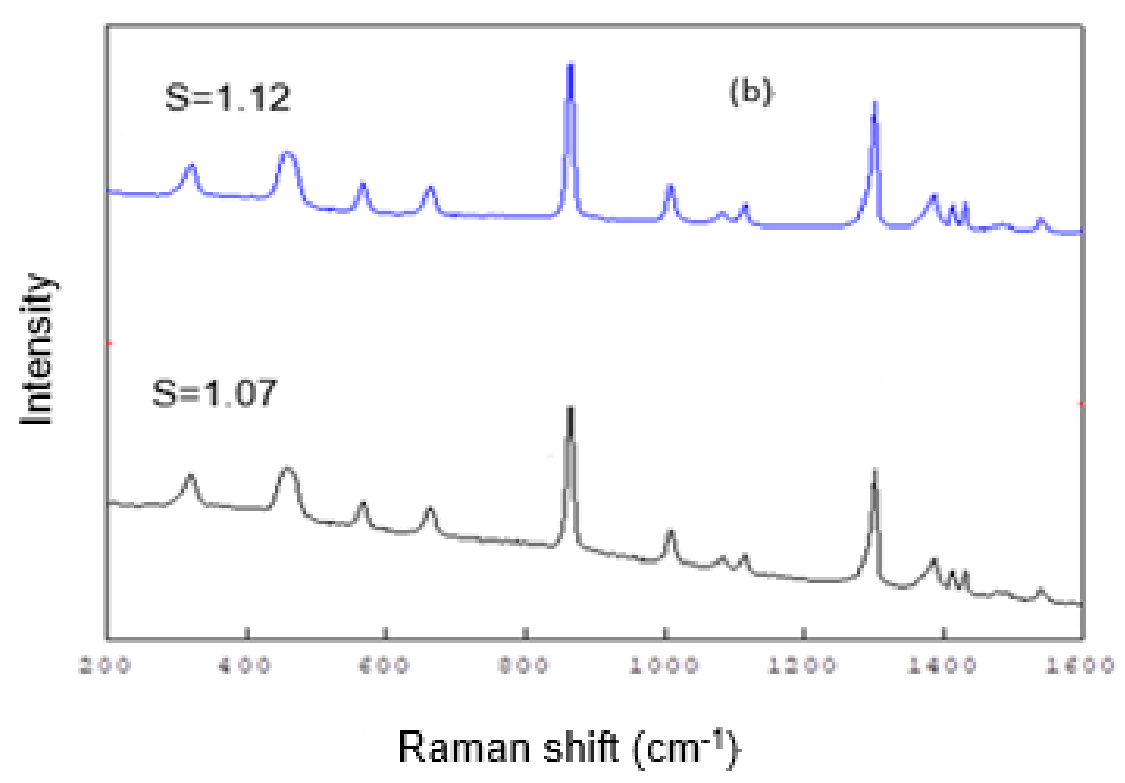

Figure 2. The Raman spectra of the produced L-glycine crystals at $S=1.07$ and $S=1.12$ for (a) $C_{i m}=0$ and (b) $C_{i m}=10 \mathrm{~kg} / \mathrm{m}^{3}$, respectively.

\section{Results and Discussion}

The induction time data of aqueous L-glycine solutions were measured for various supersaturations at $303 \mathrm{~K}$ in the presence of L-arginine for various impurity concentrations, $C_{i m}$. The average induction times are listed in Table 1 . The average lag times for the induction time data are listed in Table 2 , which were measured based on $b \cong 0.038 \mathrm{~K} / \mathrm{s}$ adopted for cooling the heated supersaturated solution to the desired constant temperature. The lag time corresponds to the time required for the heated solution to be lowered to $303 \mathrm{~K}$. Thus, as the temperature range $\Delta T_{m}$ increases, the lag time increases. The MSZW data of aqueous L-glycine solutions saturated at $T_{0}=318 \mathrm{~K}$ were measured for various $b$ in the presence of L-arginine for $C_{i m}=0-10 \mathrm{~kg} / \mathrm{m}^{3}$. The average MSZWs are listed in Table 3 . Note that $M_{w}=0.075 \mathrm{~kg} / \mathrm{mol}, \rho_{c}=1607 \mathrm{~kg} / \mathrm{m}^{3}$, and $v=7.757 \times 10^{-29} \mathrm{~m}^{3}$ for L-glycine.

Table 1. The average induction times, $t_{i}$, in the induction time measurements for various impurity concentrations, $C_{i m}$, and supersaturations, $S$, at $303 \mathrm{~K}$. The standard deviations in the least significant digits are given in parentheses.

\begin{tabular}{ccccc}
\hline \multirow{2}{*}{$C_{\boldsymbol{i} \boldsymbol{m}}\left(\mathbf{k g} / \mathbf{m}^{3}\right)$} & \multicolumn{4}{c}{$\boldsymbol{t}_{\boldsymbol{i}}\left(\times \mathbf{1 0}^{\mathbf{2}} \mathbf{s}\right)$} \\
\cline { 2 - 5 } & $\boldsymbol{S = \mathbf { 1 . 0 7 }}$ & $\boldsymbol{S = \mathbf { 1 . 0 8 }}$ & $S=\mathbf{1 . 1 0}$ & $S=\mathbf{1 . 1 2}$ \\
\hline 0 & $27(5.9)$ & $14(2.8)$ & $8.3(2.5)$ & $4.4(2.0)$ \\
2 & $62(15)$ & $33(7.3)$ & $16(4.6)$ & $8.2(2.5)$ \\
5 & $107(17)$ & $48(8.9)$ & $23(5.1)$ & $12(3.0)$ \\
10 & $154(21)$ & $62(11)$ & $31(8.8)$ & $16(4.7)$ \\
\hline
\end{tabular}


Table 2. The average lag time, $\Delta T_{m} / b$, based on $b \cong 0.038 \mathrm{~K} / \mathrm{s}$ in the induction time measurements for various impurity concentrations, $C_{i m}$, and supersaturations, $S$, at $303 \mathrm{~K}$, where $\Delta T_{m}$ corresponds to the temperature range for a solution with concentration $C_{0}$ saturated at $T_{0}$ and cooled to $303 \mathrm{~K}$. Note that $\Delta T_{m}=T_{0}-303 \mathrm{~K}$ and $S=C_{0} / C_{e q}(303 \mathrm{~K})$. The standard deviations in the least significant digits are given in parentheses.

\begin{tabular}{|c|c|c|c|c|}
\hline \multirow[b]{2}{*}{$C_{i m}\left(\mathrm{~kg} / \mathrm{m}^{3}\right)$} & \multicolumn{4}{|c|}{$\Delta T_{m} / b(\mathrm{~s})$} \\
\hline & $\begin{array}{c}S=1.07 \\
\left(\Delta T_{m}=5.1 \mathrm{~K}\right)\end{array}$ & $\begin{array}{c}S=1.08 \\
\left(\Delta T_{m}=5.8 \mathrm{~K}\right)\end{array}$ & $\begin{array}{c}S=1.10 \\
\left(\Delta T_{m}=7.2 \mathrm{~K}\right)\end{array}$ & $\begin{array}{c}S=1.12 \\
\left(\Delta T_{m}=8.7 \mathrm{~K}\right)\end{array}$ \\
\hline 0 & 135 (14) & $153(16)$ & 177 (16) & 236 (19) \\
\hline 2 & 127 (12) & 144 (13) & 195 (17) & $221(17)$ \\
\hline 5 & 141 (13) & 159 (15) & $182(16)$ & 232 (17) \\
\hline 10 & $146(15)$ & $163(14)$ & 188 (18) & $241(22)$ \\
\hline
\end{tabular}

Table 3. The average MSZWs, $\Delta T_{m}$, in the MSZW measurements for a solution saturated at $T_{0}=318 \mathrm{~K}$ cooled at various impurity concentrations, $C_{i m}$, and cooling rates. The standard deviations in the least significant digits are given in parentheses.

\begin{tabular}{ccccc}
\hline \multirow{2}{*}{$C_{\boldsymbol{i} \boldsymbol{m}}\left(\mathbf{k g} / \mathbf{m}^{\mathbf{3}}\right)$} & \multicolumn{4}{c}{$\Delta \boldsymbol{T}_{\boldsymbol{m}}(\mathbf{K})$} \\
\cline { 2 - 5 } & $\boldsymbol{b}=\mathbf{0 . 0 0 4 1 7 ~ K / \mathbf { s }}$ & $\boldsymbol{b}=\mathbf{0 . 0 0 8 3 3 ~ \mathbf { ~ } / \mathbf { s }}$ & $\boldsymbol{b}=\mathbf{0 . 0 1 1 1 1} \mathbf{K} / \mathbf{s}$ & $\boldsymbol{b}=\mathbf{0 . 0 1 3 8 9 ~} \mathbf{~} / \mathbf{s}$ \\
\hline 0 & $6.9(1.6)$ & $8.5(1.7)$ & $9.1(2.1)$ & $9.9(2.2)$ \\
2 & $8.4(1.8)$ & $10.3(2.0)$ & $11.7(2.3)$ & $12.2(2.3)$ \\
5 & $9.7(2.1)$ & $12.2(2.5)$ & $13.8(2.9)$ & $14.4(3.1)$ \\
10 & $11.5(2.3)$ & $13.9(2.4)$ & $16.1(2.7)$ & $18.8(3.3)$ \\
\hline
\end{tabular}

Table 1 indicates that $t_{i}$ increases significantly with increasing $C_{i m}$ for each $S$ and decreases with increasing $S$ for each $C_{i m}$. Thus, L-arginine exerts a nucleation inhibition effect in aqueous L-glycine solutions, which increases with increasing $C_{i m}$. Table 2 indicates that $\Delta T_{m} / b$, increases slightly with increasing $S$ for each $C_{i m}$ and remains nearly independent of $C_{i m}$. Note that $\Delta T_{m}$ corresponds to the temperature range for a solution saturated at $T_{0}$ cooled to $303 \mathrm{~K}$, where $T_{0}$ increases with increasing $S$ and remains nearly independent of $C_{i m}$. For example, $\Delta T_{m} / b=236 \mathrm{~s}$ is quite significant compared with $t_{i}=442 \mathrm{~s}$ at $S=1.12$ $\left(\Delta T_{m}=8.7 \mathrm{~K}\right)$ for $C_{i m}=0$. On the other hand, $\Delta T_{m} / b=135 \mathrm{~s}$ is negligible compared with $t_{i}=2672 \mathrm{~s}$ at $S=1.07\left(\Delta T_{m}=5.1 \mathrm{~K}\right)$ for $C_{i m}=0$.

Figure 3 shows plots of $\ln t_{i}$ against $\ln ^{2} S_{m}$ for each $C_{i m}$ according to Equation (6) based on the induction time data without consideration of the lag time. Figure 4 shows plots of $\ln \left(\Delta T_{m} / 2 b+t_{i}\right)$ against $\ln ^{2} S_{m}$ for each $C_{i m}$ according to Equation (5) based on the induction time data with consideration of the lag time. Calculated values of $\gamma$ and $A$ from the slope and intercept of the best-fit plots for each $C_{i m}$ are listed in Table 4 . Note that the regression coefficient, $R^{2}$, with the lag time is generally greater than that without the lag time for each $C_{i m}$, which indicates that Equation (5) with the lag time fits the induction time data better than Equation (6) without the lag time. 


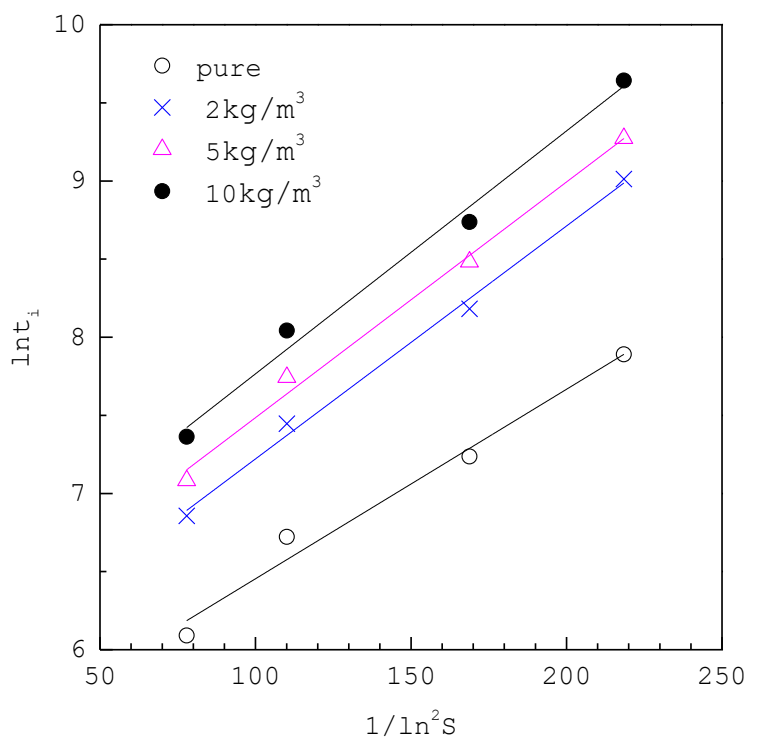

Figure 3. Plots of $\ln t_{i}$ against $\ln ^{2} S_{m}$ for various impurity concentrations, $C_{i m}$, according to Equation (6) based on the induction time data without consideration of the lag time.

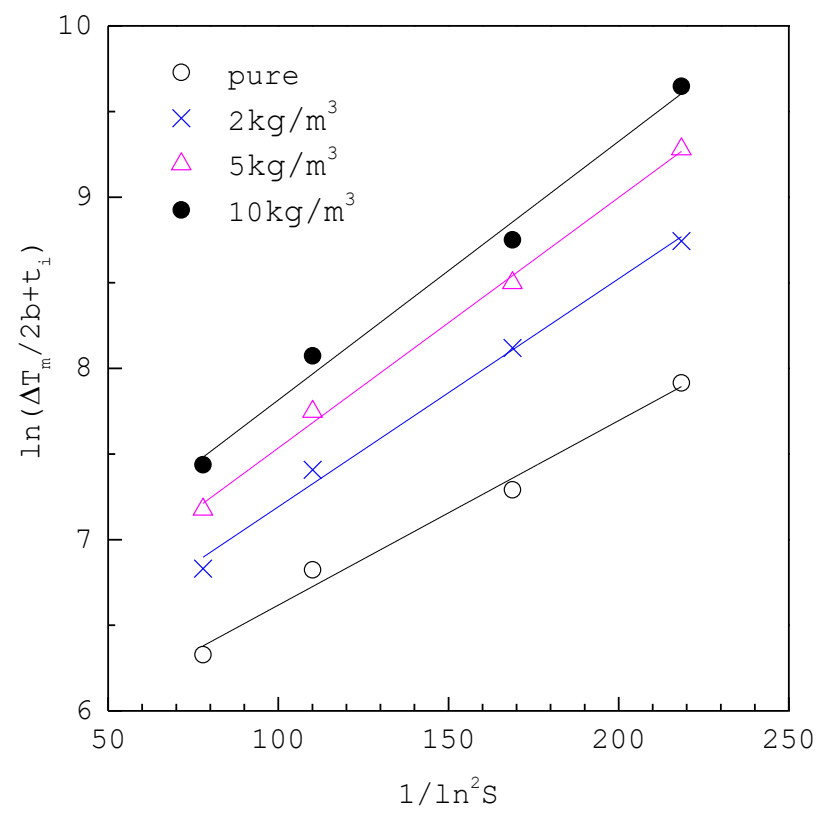

Figure 4. Plots of $\ln \left(\Delta T_{m} / 2 b+t_{i}\right)$ against $\ln ^{2} S_{m}$ for various impurity concentrations, $C_{i m}$, according to Equation (5) based on the induction time data with consideration of the lag time.

Table 4. Calculated values of $\gamma$ and $A$ with the regression coefficients, $R^{2}$, based on the induction time data. The number before the slash represents the value without consideration of the lag time and the number after the slash represents the value with consideration of the lag time.

\begin{tabular}{cccc}
\hline$C_{i m}\left(\mathbf{k g} / \mathbf{m}^{\mathbf{3}}\right)$ & $\gamma\left(\mathbf{m J} / \mathbf{m}^{\mathbf{2}}\right)$ & $\boldsymbol{A}\left(\mathbf{m}^{-\mathbf{3}} \mathbf{s}^{-\mathbf{1}}\right)$ & $\boldsymbol{R}^{\mathbf{2}}$ \\
\hline 0 & $2.07 / 1.99$ & $26.5 / 19.7$ & $0.981 / 0.987$ \\
2 & $2.17 / 2.13$ & $16.9 / 14.3$ & $0.991 / 0.994$ \\
5 & $2.22 / 2.20$ & $12.7 / 11.6$ & $0.993 / 0.997$ \\
10 & $2.24 / 2.22$ & $10.0 / 9.1$ & $0.989 / 0.990$ \\
\hline
\end{tabular}

As indicated in Table 4, one can note that the value of $\gamma$ with the lag time, $\gamma_{l a g}$, is lower by about $2 \%$ than that without the lag time, $\gamma$, while the value of $A$ with the lag time, 
$A_{\text {lag }}$, is lower by about $15 \%$ than that without the lag time, $A$. These findings are consistent with $\gamma_{\text {lag }}<\gamma$ and $A_{\text {lag }}<A$ derived in Supplementary Materials.

Table 3 indicates that $\Delta T_{m}$ increases with increasing $C_{i m}$ for each $b$ and increases with increasing $b$ for each $C_{i m}$. Thus, as similar to the results from the induction time data, L-arginine exerts a nucleation inhibition effect in aqueous L-glycine solutions, which increases with increasing $C_{i m}$. Figure 5 shows plots of $\left(T_{0} / \Delta T_{m}\right)^{2}$ against $\ln \left(\Delta T_{m} / b\right)$ for various $C_{i m}$ according to Equation (9) based on the MSZW data. Calculated values of $\gamma$ and $A$ from the slope and intercept of the best-fit plots for each $C_{i m}$ are listed in Table 5 .

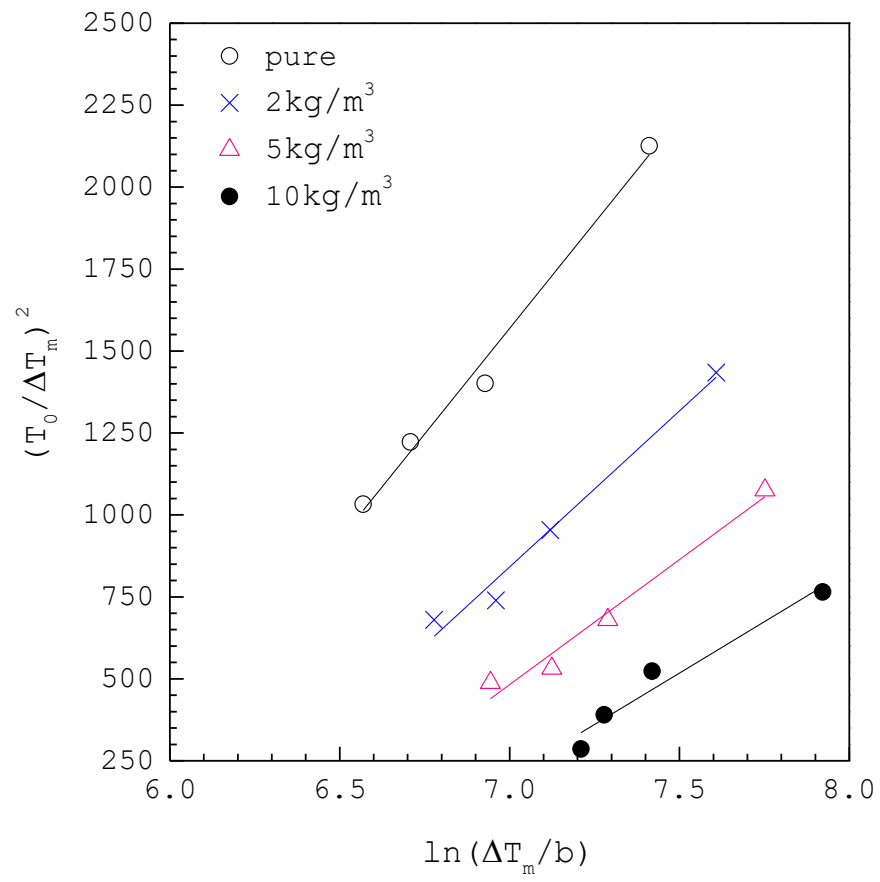

Figure 5. Plots of $\left(T_{0} / \Delta T_{m}\right)^{2}$ against $\ln \left(\Delta T_{m} / b\right)$ for various impurity concentrations, $C_{i m}$, according to Equation (9) based on the MSZW data.

Table 5. Calculated values of $\gamma$ and $A$ with the regression coefficients, $R^{2}$, based on the MSZW data.

\begin{tabular}{cccc}
\hline$C_{\boldsymbol{i m}}\left(\mathbf{k g} / \mathbf{m}^{\mathbf{3}}\right)$ & $\gamma\left(\mathbf{m} \mathbf{J} \mathbf{m}^{\mathbf{2}}\right)$ & $\boldsymbol{A}\left(\mathbf{m}^{-\mathbf{3}} \mathbf{s}^{-\mathbf{1}}\right)$ & $\boldsymbol{R}^{\mathbf{2}}$ \\
\hline 0 & 2.13 & 30.9 & 0.990 \\
2 & 2.36 & 22.1 & 0.981 \\
5 & 2.54 & 17.2 & 0.975 \\
10 & 2.71 & 12.6 & 0.953 \\
\hline
\end{tabular}

The values of $\gamma$ and $A$ obtained from the MSZW data in Table 5 are consistent with those obtained from the induction time data in Table 4. They all indicate that, as $C_{i m}$ increases, $\gamma$ increases slightly while $A$ decreases quite significantly. For example, as $C_{i m}$ increases from 0 to $10 \mathrm{~kg} / \mathrm{m}^{3}, \gamma$ only increases slightly in the range of $10 \%$ to $30 \%$, while $A$ decreases significantly in the range of $50 \%$ to $60 \%$. It is speculated that the presence of $\mathrm{L}$-arginine in the aqueous L-glycine solution leads to some L-arginine molecules adsorbed on the nucleus surface of L-glycine, which suppresses nucleation and results in a higher $\gamma$ compared to that without L-arginine adsorbed on the nucleus surface of L-glycine. On the other hand, the presence of L-arginine in the aqueous L-glycine solution suppresses nucleation and results in a lower $A$ compared to that without L-arginine in the aqueous $\mathrm{L}$-glycine solution. As the effects of L-arginine impurity on $\gamma$ and $A$ become more profound at a greater concentration of L-arginine impurity, a greater $C_{i m}$ results in a higher $\gamma$ and a lower $A$. This trend is consistent with the finding reported by Heffernan et al. [8] for the 
nucleation of curcumin in propan-2-ol due to the presence of demethoxycurcumin and bisdemethoxycurcumin.

\section{Conclusions}

A model was proposed based on CNT to determine the nucleation parameters from both the induction and MSZW data. The unique feature is that the derivation of this model for both the induction and MSZW data is based on the same assumption that the nucleation point corresponds to the formation of a single primary nucleus in a supersaturated solution. This model results in two different equations. One is derived for the induction data while the other is derived for the MESZW data. The proposed model was applied to calculate the interfacial free energy and pre-exponential nucleation factor from both the induction time data and the MSZW data for the aqueous L-glycine solutions in the presence of L-arginine impurity. The results indicated that the values of interfacial free energy and pre-exponential nucleation factor obtained from the MSZW data are consistent with those obtained from the induction time data. The induction time data with consideration of the lag time lead to a lower interfacial free energy and a lower pre-exponential nucleation factor than those for the induction time data without consideration of the lag time. As the impurity concentration increases, the interfacial free energy increases slightly while the pre-exponential nucleation factor decreases quite significantly based on both the induction time and MSZW data.

Supplementary Materials: The following are available online at https:/ /www.mdpi.com/article/10 $.3390 /$ cryst11101226/s1, The derivation of $\gamma_{\text {lag }}<\gamma$ and $A_{\text {lag }}<A$.

Funding: This research was funded by Chang Gung Memorial Hospital (CMRPD2K0012) and Ministry of Science and Technology of Taiwan (MOST108-2221-E-182-034-MY2).

Data Availability Statement: Not applicable.

Acknowledgments: The author would like to thank Chang Gung Memorial Hospital (CMRPD2K0012) and Ministry of Science and Technology of Taiwan (MOST108-2221-E-182-034-MY2) for financial support of this research. The author also expresses his gratitude to Pin-Jhu Li and Dai-Rong Wu for their experimental work.

Conflicts of Interest: The authors declare no conflict of interest.

\section{Notation}

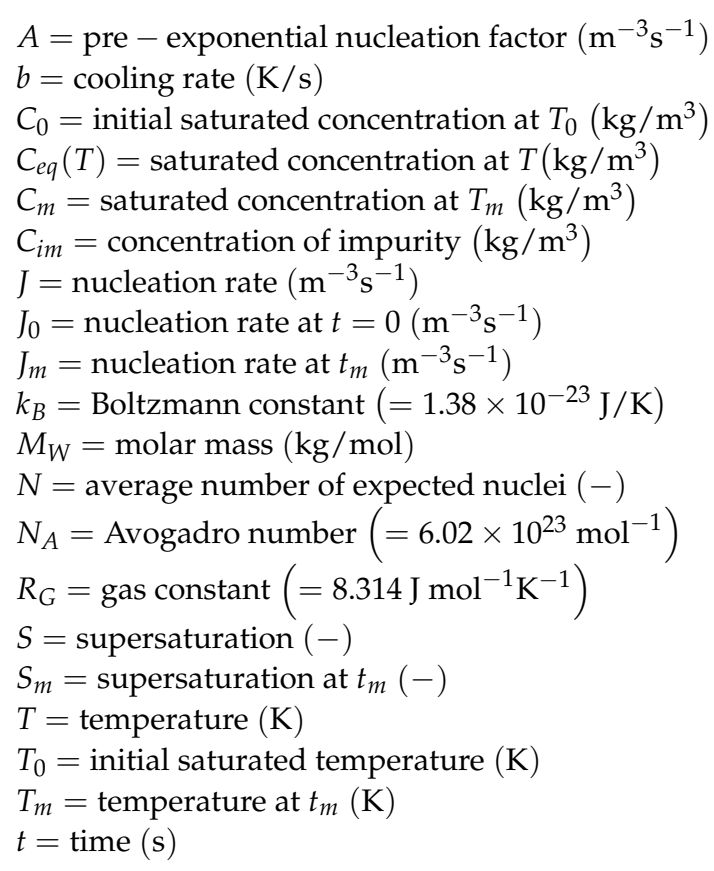




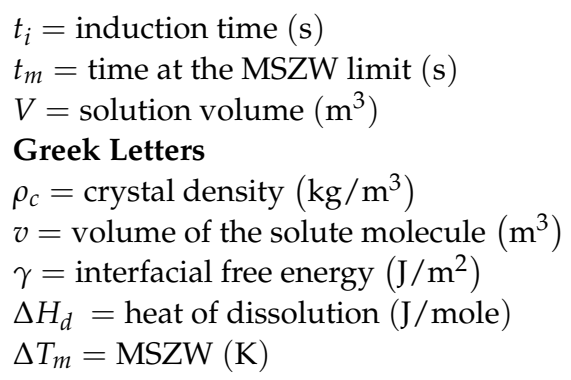

\section{References}

1. Mullin, J.W. Crystallization, 3rd ed.; Butterworth-Heinemann: Oxford, UK, 1993.

2. Kashchiev, D. Nucleation: Basic Theory with Applications; Butterworth-Heinemann: Oxford, UK, 2000.

3. Kashchiev, D.; van Rosmalen, G.M. Review: Nucleation in solutions revisited. Cryst. Res. Technol. 2003, 38, 555-574. [CrossRef]

4. Dhanasekaran, P.; Srinivasan, P. Nucleation control, separation and bulk growth of metastable $\alpha$-L-glutamic acid single crystals in the presence of L-tyrosine. J. Cryst. Growth. 2013, 364, 23-29. [CrossRef]

5. Peng, J.; Dong, Y.; Wang, L.; Li, L.L.; Li, W.; Feng, H. Effect of impurities on the solubility, metastable zone width, and nucleation kinetics of borax decahydrate. Ind. Eng. Chem. Res. 2014, 53, 12170-12178. [CrossRef]

6. Siepermann, C.A.P.; Huang, S.; Myerson, A.S. Nucleation inhibition of benzoic acid through solution complexation. Cryst. Growth Des. 2017, 17, 2646-2653. [CrossRef]

7. Yang, L.; Cao, J.; Luo, T. Effect of $\mathrm{Mg}^{2+}, \mathrm{Al}^{3+}$, and $\mathrm{Fe}^{3+}$ ions on crystallization of type $\alpha$ hemi-hydrated calcium sulfate under simulated conditions of hemi-hydrate process of phosphoric acid. J. Cryst. Growth 2018, 486, 30-37. [CrossRef]

8. Heffernan, C.; Ukrainczyk, M.; Zeglinski, J.; Hodnett, B.K.; Rasmuson, A.C. Influence of structurally related impurities on the crystal nucleation of curcumin. Cryst. Growth Des. 2018, 18, 4715-4723. [CrossRef]

9. Su, N.; Wang, Y.; Xiao, Y.; Lu, H.; Lou, Y.; Huang, J.; He, J.; Li, Y.; Hao, H. Mechanism of influence of organic impurity on crystallization of sodium sulfate. Ind. Eng. Chem. Res. 2018, 57, 1705-1713. [CrossRef]

10. Bodnar, K.; Hudson, S.P.; Rasmuson, A.C. Promotion of mefenamic acid nucleation by a surfactant additive, docusate sodium. Cryst. Growth Des. 2019, 19, 591-603. [CrossRef]

11. Keshavarz, L.; Steendam, R.R.E.; Blijlevens, M.A.R.; Pishnamazi, M.; Frawley, P.J. Influence of impurities on the solubility, nucleation, crystallization, and compressibility of paracetamol. Cryst. Growth Des. 2019, 19, 4193-4201. [CrossRef]

12. Huang, Y.; Lu, J.; Chen, H.; Du, W.; Wang, X. Effects of succinic acid and adipic acid on the metastable width of glutaric acid in acetic acid. J. Cryst. Growth. 2019, 507, 1-9. [CrossRef]

13. Chen, J.; Peng, J.; Wang, X.; Dong, Y.; Li, W. Effects of $\mathrm{CO}_{3}{ }^{2-}$ and $\mathrm{OH}^{-}$on the solubility, metastable zone width and nucleation kinetics of borax decahydrate. R. Soc. Open Sci. 2019, 6, 181862. [CrossRef]

14. Luo, M.; Liu, C.; Song, X.; Yu, J. Effects of $\mathrm{Al}_{2}\left(\mathrm{SO}_{4}\right)_{3}$ and $\mathrm{K}_{2} \mathrm{SiO}_{3}$ impurities on the crystallization of $\mathrm{K}_{2} \mathrm{SO}_{4}$ from aqueous solutions. Cryst. Res. Technol. 2021, 56, 2000052. [CrossRef]

15. Kubota, N. A new interpretation of metastable zone widths measured for unseeded solutions. J. Cryst. Growth 2008, 310, 629-634. [CrossRef]

16. Sangwal, K. Effects of impurities on the metastable zone width of solute-solvent systems. J. Cryst. Growth 2009, 311, 4050-4061. [CrossRef]

17. Shiau, L.D.; Lu, T.S. A model for determination of the interfacial energy from the measured metastable zone width by the polythermal method. J. Cryst. Growth 2014, 402, 267-272. [CrossRef]

18. Shiau, L.D.; Lu, T.S. A model for determination of the interfacial energy from the induction time or metastable zone width data based on turbidity measurements. CrystEngComm 2014, 16, 9743-9752. [CrossRef]

19. Yang, H.; Florence, A.J. Relating induction time and metastable zone width. CrystEngComm 2017, 19, 3966-3978. [CrossRef]

20. Li, Z.; Si, A.; Yan, Y.; Zhang, X.; Yang, H. Interaction of metastable zone width and induction time based on nucleation potential. Ind. Eng. Chem. Res. 2020, 59, 22597-22604.

21. Shiau, L.D.; Wu, D.R. Effect of L-valine impurity on the nucleation parameters of aqueous L-glutamic acid solutions from metastable zone width. J. Cryst. Growth 2020, 546, 125790. [CrossRef]

22. Chu, G.; Vilensky, R.; Vasilyev, G.; Martin, P.; Zhang, R.; Zussman, E. Structure evolution and drying dynamics in sliding cholesteric cellulose nanocrystals. J. Phys. Chem. Lett. 2018, 9, 1845-1851. [CrossRef]

23. Khadem, S.A.; Rey, A.D. Nucleation and growth of cholesteric collagen tactoids: A time-series statistical analysis based on integration of direct numerical simulation (DNS) and long short-term memory recurrent neural network (LSTM-RNN). J. Colloid Interface Sci. 2021, 582, 859-873. [CrossRef] [PubMed]

24. Towler, C.S.; Davey, R.J.; Lancaster, R.W.; Price, C.J. Impact of molecular speciation on crystal nucleation in polymorphic systems: the conundrum of $\gamma$ glycine and molecular 'self-poisoning'. J. Am. Chem. Soc. 2004, 126, 13347-13353. [CrossRef] [PubMed]

25. Sun, X.; Garetz, B.A.; Myerson, A.S. Supersaturation and polarization dependence of polymorph control in the nonphotochemical laser-induced nucleation(NPLIN) of aqueous glycine solutions. Cryst. Growth Des. 2006, 6, 684-689. [CrossRef] 
26. Bouchard, A.; Hofland, G.W.; Witkamp, G.J. Solubility of glycine polymorphs and recrystallization of $\beta$-glycine. J. Chem. Eng. Data 2007, 52, 1626-1629. [CrossRef]

27. Srinivasan, P.; Indirajith, R.; Gopalakrishnan, R. Growth and characterization of $\alpha$ and $\gamma$-glycine single crystals. J. Cryst. Growth 2011, 318, 762-767. [CrossRef]

28. Han, G.; Chow, P.S.; Tan, R.B.H. Direct comparison of $\alpha$ - and $\gamma$-glycine growth rates in acidic and basic solutions: New insights into glycine polymorphism. Cryst. Growth Des. 2012, 12, 2213-2220. [CrossRef]

29. Yani, Y.; Chow, P.S.; Tan, R.B.H. Glycine open dimers in solution: New insights into $\alpha$-glycine nucleation and growth. Cryst. Growth Des. 2012, 12, 4771-4778. [CrossRef]

30. Devi, K.R.; Srinivasan, K. A novel approach to understand the nucleation kinetics of $\alpha$ and $\gamma$ polymorphs of glycine from aqueous solution in the presence of a selective additive through charge compensation mechanism. CrystEngComm 2014, 16, 707-722. [CrossRef]

31. Shiau, L.D. Comparison of the interfacial energy and pre-exponential factor calculated from the induction time and metastable zone width data based on classical nucleation theory. J. Cryst. Growth 2016, 450, 50-55. [CrossRef]

32. Jiang, S.; ter Horst, J.H. Crystal nucleation rates from probability distributions of induction times. Cryst. Growth Des. 2011, 11, 256-261. [CrossRef]

33. Kadam, S.S.; Kramer, H.J.M.; ter Horst, J.H. Combination of a single primary nucleation event and secondary nucleation in crystallization processes. Cryst. Growth Des. 2011, 11, 1271-1277. [CrossRef]

34. Kadam, S.S.; Kulkarni, S.A.; Coloma Ribera, R.; Stankiewicz, A.I.; ter Horst, J.H. A new view on the metastable zone width during cooling crystallization. Chem. Eng. Sci. 2012, 72, 10-19. [CrossRef]

35. Green, D.W.; Perry, R.H. Perry's Chemical Engineers' Handbook, 8th ed.; McGraw Hill Book Company: New York, NY, USA, 2008.

36. Park, K.; Evans, J.M.B.; Myerson, A.S. Determination of Solubility of Polymorphs Using Differential Scanning Calorimetry. Cryst. Growth Des. 2003, 3, 991-995. [CrossRef]

37. Murli, C.; Thomas, S.; Venkateswaran, S.; Sharma, S.M. Raman spectroscopic investigation of $\alpha$-glycine at different temperatures. Phys. B 2005, 364, 233-238. [CrossRef] 